\title{
COMPORTAMENTO REPRODUTIVO DE Dendrocephalus brasiliensis, Pesta 1921 (CRUSTACEA: ANOSTRACA)
}

\author{
José Patrocínio Lopes ${ }^{1}$, Hélio de Castro Bezerra Gurgel ${ }^{2}$, Cibele SoAres Pontes $^{2}$
}

${ }^{1}$ Assistente Técnico da Eletrobrás CHESF, Paulo Afonso, BA - jlopes@chesf.gov.br

${ }^{2}$ Professores Doutores da Universidade Federal do Rio Grande do Norte, Natal, RN

\section{RESUMO}

O comportamento reprodutivo de anostráceos de água doce tem sido pouco divulgado na literatura especializada em carcinologia, especificamente em relação ao Dendrocephlaus brasiliensis Pesta, 1921, havendo apenas dados abundantes sobre a distribuição geográfica desse anostráceo dulciaquícola. O objetivo deste trabalho foi conhecer o comportamento reprodutivo desse Anostraca, em diferentes períodos (seco e chuvoso). Para isto, foram utilizados indivíduos maduros de ambos os sexos coletados em quatro viveiros da Estação de Piscicultura de Paulo Afonso (EPPA), por meio de captura mensal em cada viveiro, durante o período de dezembro de 2004 a novembro de 2005. O tipo de reprodução foi observado através da colocação em aquários, de algumas fêmeas juntas com machos e outras individualmente, a partir da fase de náuplios, onde permaneceram por 15 dias (idade reprodutiva). A proporção sexual dos indivíduos foi calculada através das frequências relativas de machos e de fêmeas, a cada mês, para todo o período de coleta. Aos 10 dias é possível produção de cistos e o número desses está relacionado ao tamanho da fêmea. A relação macho:fêmea no período de estudo foi de 1 macho para 1,07 fêmea. A proporção macho:fêmeas foi de $51,75 \%$ de fêmea para $48,25 \%$ de machos ao longo do ano. Foi observado, por meio do comportamento reprodutivo, tratar-se de reprodução sexuada.

PALAVRAS-CHAVE: água doce; crustáceo; reprodução; Thamnocephalidae.

\section{REPRODUCTIVE BEHAVIOR OF Dendrocephalus brasiliensis, Pesta 1921 (CRUSTACEAN: ANOSTRACA)}

The reproductive behavior of fresh water Anostracan has
not been massively studied by the carcinology specialized
literature, regarding especially the Dendrocephalus
brasiliensis Pesta, 1921 , about which there are abundant
studies only on the geographical distribution of that
Anostracan. The objective of this research was to
investigate the reproductive behavior of this Anostracan in
different periods (dry and rainy). For this, mature
individuals of both sexes were used. They were collected
in four ponds of the Fish Farming Station of Paulo Afonso
(FFSPA), by monthly capture in each pond, within the
period from December 2004 to November 2005 . The
reproduction type was observed by placing some females

\section{ABSTRACT}

in aquariums with males and placing the other ones individually, starting from the nauplii phase, where they stayed for 15 days (reproductive age). The individuals' sexual proportion was calculated by the relative frequencies of males and of females, every month, for the whole collection period. At 10 days cysts production is possible and the number of produced cysts is related to the size of the female. The ratio male:female in the studied period was of 1 male to 1.07 female. The proportion male:female was $51.75 \%$ female to $48.25 \%$ male along the year. The observation of the reproductive behavior showed the reproduction is sexed.

KEYWORDS: crustacean; fresh water; reproduction; Thamnocephalidae. 


\section{INTRODUÇÃO}

No Brasil, especificamente no Nordeste, a introdução de espécies exóticas de crustáceos (camarões, Artemia sp.) e de peixes (tilápias, carpas) costumava ser efetuada sem um estudo prévio das consequências que isso poderia proporcionar ao meio ambiente. Atualmente, com o surgimento de muitas doenças, principalmente em crustáceos (camarões), os órgãos ambientais têm sido mais severos com relação à importação de espécies exóticas. Diante do exposto, o presente trabalho aborda aspectos ambientais, morfológicos e de comportamento reprodutivo de branchoneta, Dendrocephalus brasiliensis, Pesta 1921, espécie continental, comum em vários estados brasileiros e que poderá ser a coadjuvante da espécie exótica Artemia sp.

$\mathrm{Na}$ aquicultura praticada na atualidade, um dos maiores problemas enfrentados, principalmente na larvicultura de camarões e peixes, é a demanda por alimento vivo (na forma de cistos, náuplios, larvas, alevinos ou juvenis de artêmia ou peixes) ou inerte (biomassa congelada). Artemia sp. é um alimento de sustentação na larvicultura de camarões e peixes; contudo, o alto custo para cistos do Great Salt Lake (GSL), Utah, Estados Unidos, classe A, em torno de U\$ 100.00/kg, aliado à escassez no mercado, restringe o crescimento do cultivo dessas espécies. A espécie exótica Artemia sp. apresenta comportamento reprodutivo determinado pelas condições impostas pela natureza. Sob condições favoráveis, essa espécie realiza extensa produção de cistos. No entanto, quando em condições de estresse, as fêmeas liberam náuplios pelo processo de ovoviviparidade. Trata-se do anostráceo mais estudado e utilizado na aquicultura como alimento vivo (cistos e náuplios) ou congelado (biomassa) para peixes e camarões (CÂMARA, 2000).

Sendo restrito a ambientes lênticos e/ou temporários, $D$. brasiliensis, pode estabelecer-se na aquicultura (uma vez que os viveiros de cultivo são constantemente esvaziados e reabastecidos de acordo com a produção de alevinos, além disso, sua capacidade de produzir cistos torna difícil a sua eliminação (MAI et al., 2008).

$\mathrm{Na}$ espécie $D$. brasiliensis, somente é observada reprodução por meio da liberação de cistos, seja em condições ideais no ambiente de cultivo com temperatura na faixa de $26^{\circ} \mathrm{C}$, oxigênio dissolvido na água em torno de $5 \mathrm{mg} / \mathrm{L}$ e abundância de algas na sua alimentação, sendo possível, nessas condições ambientais, obter-se uma produção de $2.075 \mathrm{~g}$ de cistos/ha/ano, seja em ambiente estressante como baixas temperaturas, deficiência de alimento e redução de espaço (LOPES et al., 2007). Os inúmeros trabalhos sobre esse anostráceo pouco descrevem sobre sua biologia e precisamente sobre seu comportamento reprodutivo, o que se faz necessário visando-se ao domínio de sua reprodução e posteriormente à sua inclusão na aquicultura como alimento para peixes e crustáceos.

Em face da velocidade com que atualmente esse pequeno animal vem sendo difundido em vários estados brasileiros, este trabalho é uma relevante contribuição aos estudos requeridos para a introdução dessa espécie na aquicultura. $\mathrm{O}$ objetivo deste trabalho foi, então, estudar o comportamento reprodutivo de $D$. brasiliensis nos períodos seco e chuvoso.

\section{MATERIAL E MÉTODOS}

O cultivo de branchonetas foi realizado em quatro viveiros da Estação de Piscicultura de Paulo Afonso (EPPA) de propriedade da Companhia Hidro Elétrica do São Francisco (CHESF), com área de $2000 \mathrm{~m}^{2}$ cada e profundidade média de $0,80 \mathrm{~m}$, cujas dimensões assemelham-se às lagoas temporárias, biótopos utilizados por esses anostráceos. Os aspectos morfológicos e reprodutivos foram observados em laboratório após um período de 30 dias pós-eclosão, quando o animal já tinha atingido a fase adulta. As observações sobre o comportamento reprodutivo de $D$. brasiliensis foram realizadas nos períodos chuvoso e seco.

Para identificação do sexo dos indivíduos foram utilizados exemplares maduros, já que a chave de identificação específica baseia-se, sobretudo, nas características sexuais externas: estrutura das antenas nos machos, alguns lóbulos das primeiras patas e saco ovígero nas fêmeas (COHEN, 1995).

O material biológico utilizado nesta pesquisa foi coletado de quatro viveiros da EPPA, por meio de uma captura mensal em cada viveiro, durante o período de dezembro de 2004 a novembro de 2005 , com uso de uma rede de arrasto de 0,50 x 2,00 m, confeccionada de material de náilon com malha de $1,0 \mathrm{~mm}$. O esforço de captura foi de $2 \mathrm{H} / 10 \mathrm{~min}$./dia. Foram colhidas aproximadamente 2000 branchonetas, equivalente a $0,5 \%$ dos animais dos quatro viveiros.

Para acompanhar o crescimento em peso e o comprimento dos indivíduos da espécie em estudo, após as coletas, os exemplares foram etiquetados, acondicionados em caixas isotérmicas e transferidos para laboratório da EPPA. Em seguida, foi realizado 
o procedimento de identificação macroscópica do sexo por meio da observação do ovissaco presente nas fêmeas ou pelo apêndice frontal dos machos. Foram considerados os seguintes parâmetros por exemplar: comprimento total (Lt) expresso em centímetros e obtido por meio de paquímetro digital e peso total $(\mathrm{Wt})$, em gramas, com emprego de balança digital com precisão de $0,001 \mathrm{~g}$.

Para a análise da relação peso total e o comprimento total dos machos e das fêmeas, realizou-se a distribuição dos pontos empíricos individuais dessas variáveis, considerando-se 0 comprimento total como a variável independente e o peso total como a variável dependente, de modo a estabelecer a expressão matemática que melhor se ajustasse aos dados da relação entre as variáveis envolvidas. A estrutura da população em comprimento foi baseada na distribuição das frequências relativas das classes de comprimento total, por sexo separado por período total, sendo os dados agrupados em classes de $1,0 \mathrm{~cm}$.

Para o conhecimento do comportamento reprodutivo de $D$. brasiliensis, fez-se necessário conhecer o tipo de reprodução, o tamanho e a idade em que as fêmeas estavam aptas à liberação de cistos para produção de náuplios (maturidade sexual), a relação macho/fêmea, a proporção sexual, o período de desova, a fecundidade, a longevidade e a periodicidade de reprodução.

Para conhecimento da idade e tamanho de fêmeas aptas à reprodução, exemplares de fêmeas de idades entre 10 e 40 dias de vida foram induzidos à reprodução em laboratório. Os cistos obtidos foram distribuídos em quatro provetas de $100 \mathrm{~mL}$ cada e o índice de eclosão de náuplios foi analisado. Para observação do tipo de reprodução, foi utilizado o cultivo de náuplios de branchonetas em nove aquários, medindo cada um $0,10 \times 0,20 \times 0,15 \mathrm{~m}$, desde a fase larval até a idade de reprodução, que é possível a partir dos dez primeiros dias de vida, visando a observar a ocorrência ou ausência de cópulas, conforme ocorre em Artemia sp., objetivando-se à confirmação ou não de reprodução por partenogênese. Também com a mesma intenção, náuplios da espécie foram isolados um a um, logo após a eclosão, em vidros de boca larga, telados e mergulhados em tanques fertilizados (Figura 1), visando ao seu desenvolvimento até a identificação do sexo. As fêmeas identificadas nesse processo, após 15 dias, foram transportadas para laboratório e induzidas à desova na tentativa de liberação de cistos e posteriormente produção de náuplios sem a participação de machos.

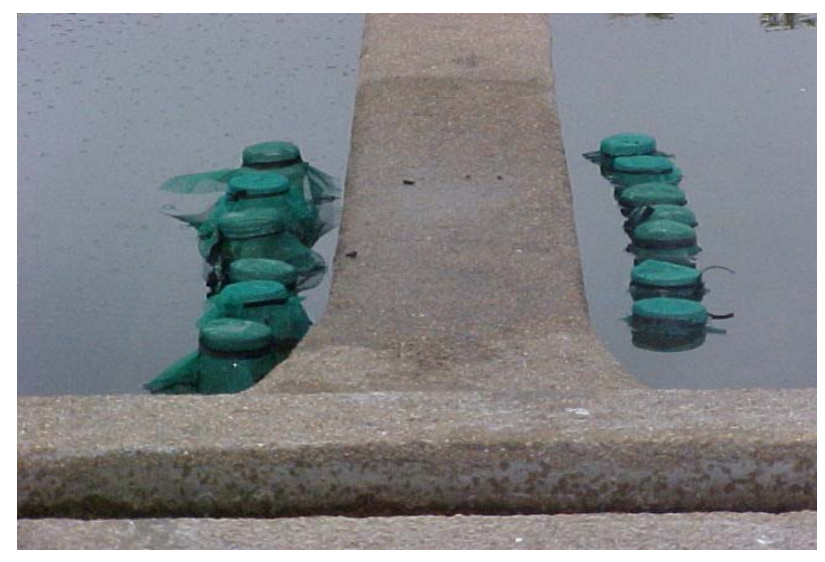

Figura 1 - Náuplios de D. brasiliensis, isolados para confirmação do sexo e tipo de reprodução.

Para a análise da proporção entre os sexos dos indivíduos capturados, foram calculadas as frequências relativas de machos e de fêmeas, por mês, para todo o período considerado. Aplicou-se o teste de qui-quadrado $\left(\chi^{2}\right)$ entre os sexos, para a detecção de diferenças estatísticas, e foi efetuada uma correlação no período inverno/verão para verificar sua possível influência.

O período de desova foi determinado com base na distribuição dos valores médios bimestrais do índice gonadossomático (IGS) para fêmeas, de acordo com a expressão de VAZOLLER (1996):

$\mathrm{IGS}=\mathrm{Wg} / \mathrm{Wt}-\mathrm{Wg}$

Em que:

$\mathrm{W}_{\mathrm{g}}$ - peso da gônada em gramas;

$\mathrm{W}_{\mathrm{t}}$ - peso total de cada indivíduo.

A fecundidade foi observada com auxílio de um microscópio binocular a partir do número de cistos liberados individualmente por fêmeas em laboratório. Já a longevidade foi monitorada em campo e em laboratório a partir de observações diárias dos indivíduos presentes nos tanques de cultivo e em aquários, respectivamente, até a ausência total desses por morte. A periodicidade de reprodução foi observada a partir de coletas mensais de fêmeas para reprodução em laboratório.

Este trabalho estudou o comportamento reprodutivo de branchoneta, $D$. brasiliensis nas diversas fases de vida: cistos, náuplios e animal adulto, com observações ao microscópio. A análise do ciclo de vida forneceu informações sobre a maturação gonadal e o tipo de reprodução. Foram descritas as características de ovos provenientes de fêmeas maduras, assim como o tipo de postura (desova). Finalmente, foram quantificados os parâmetros reprodutivos, com os índices de ovos por fêmea. 


\section{RESULTADOS}

Nas análises da relação peso-comprimento foram utilizados 720 indivíduos (360 machos e 360 fêmeas). As variáveis Wt e Lt mostraram correlação positiva, com a tendência de seus pontos apresentarem ajuste expressivo em todas as análises realizadas.
Os machos, no período de seca, tiveram a relação $\mathrm{Wt} / \mathrm{Lt}$ expressa pela equação $\mathrm{Lt}=$ $5,5084 \mathrm{Wt}^{0,3672}(\mathrm{r}=0,945 ; \mathrm{n}=180)$ e, no período chuvoso, $\mathrm{Lt}=4,9477 \mathrm{Wt}^{0,3257}(\mathrm{r}=0,955 ; \mathrm{n}=180)$. Os machos apresentaram, portanto, um crescimento em peso do tipo alométrico positivo $(b=0,3672$ e $\mathrm{b}=0,3257$ ) (Figuras $2 \mathrm{a}$ e $2 \mathrm{~b}$ ).

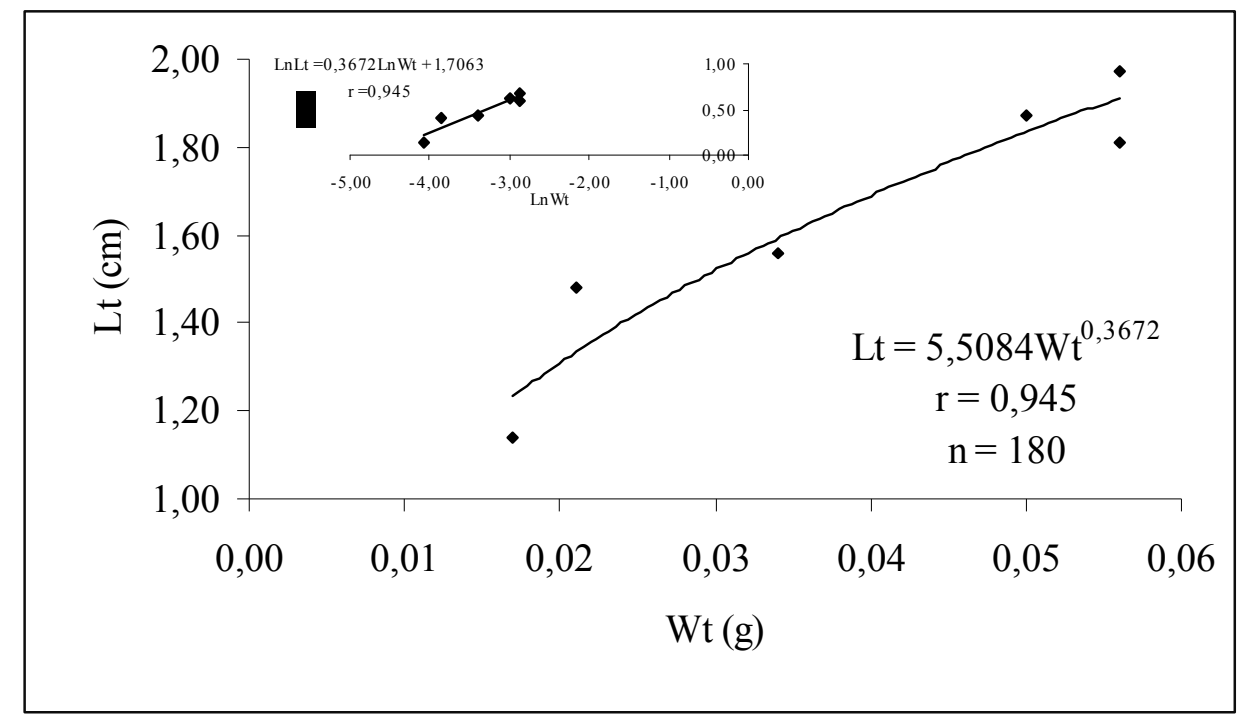

Figura 2a - Relação peso total/comprimento total e transformação logarítmica para a população (machos) de D. brasiliensis, capturados na EPPA, nos períodos de seca e chuva.

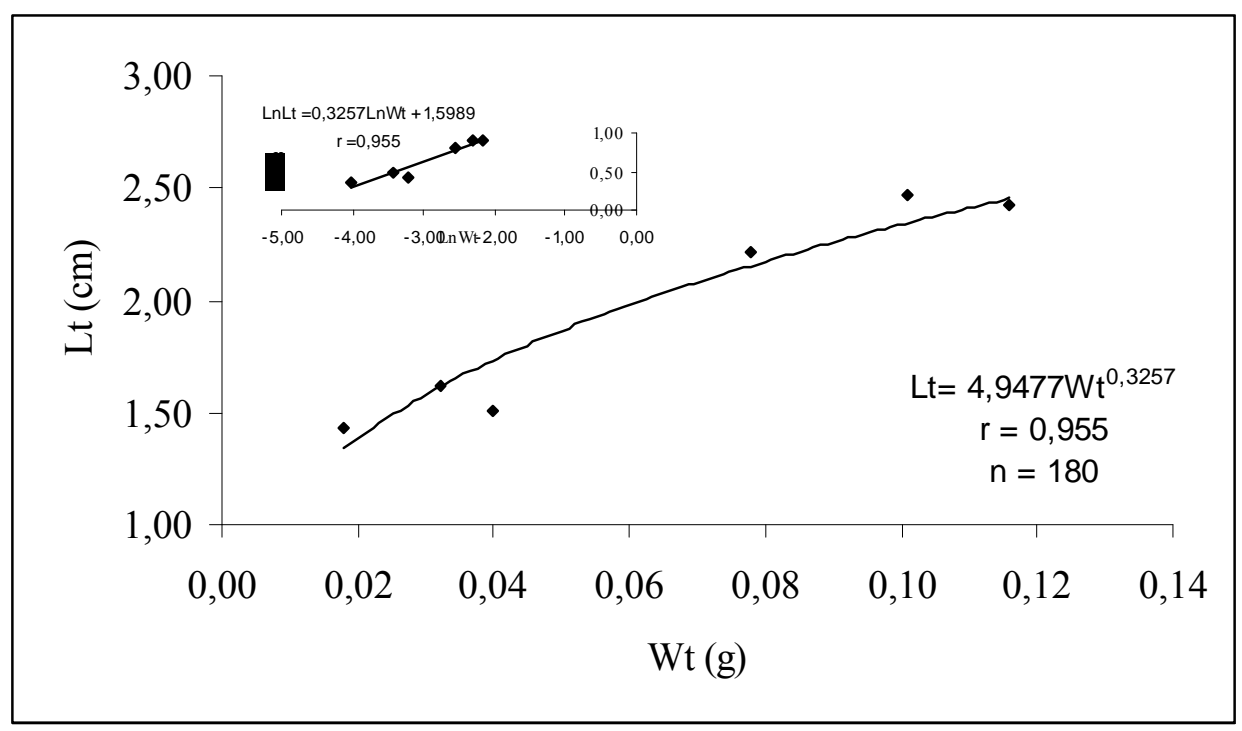

Figura 2b - Relação peso total/comprimento total e transformação logarítmica para a população (machos) de D. brasiliensis, capturados na EPPA, no período chuvoso.

A equação das fêmeas, no período de seca, foi $\mathrm{Lt}=4,1834 \mathrm{Wt}^{0,2950}(\mathrm{r}=0,986 ; \mathrm{n}=180)$, sendo caracterizada por um crescimento alométrico negativo $(\mathrm{b}=0,2950)$, o que indica um maior incremento em comprimento do que em peso. No período chuvoso, a equação foi a seguinte: $\mathrm{Lt}=$ $4,9609 \mathrm{Wt}^{0,329}(\mathrm{r}=0,901 ; \mathrm{n}=180)$, com crescimento alométrico positivo $(\mathrm{b}=0,3290) \quad$ (Figura 3). 




Figura 3 - Relação peso total/comprimento total e transformação logarítmica para a população (fêmeas) de D. brasiliensis, capturada na EPPA, nos periodos de seca e chuva.

O teste de qui-quadrado $\left(\chi^{2}\right)$, aplicado no período de verão para machos e fêmeas, revelou diferença significativa, com $95 \%$ de probabilidade do número de machos superior ao de fêmeas. Nesse teste, consideraram-se as seguintes hipóteses para as variáveis analisadas: $\mathrm{H}_{\mathrm{o}}$ - os dois grupos são iguais em média; $\mathrm{H}_{\mathrm{a}}$ - os dois grupos são diferentes em média. Para o período de inverno e ao longo do ano, o teste revelou diferença significativa, com $95 \%$ de probabilidade do número de fêmeas superior ao de machos.

As branchonetas utilizadas neste estudo nascem e crescem, vivendo em média 60 dias em viveiros da Estação de Piscicultura de Paulo Afonso, onde se pratica alevinagem das seguintes espécies: Prochilodus argenteus (Curimatã pacu), Prochilodus costatus (Curimatã piau), Colossoma macropomum (Tambaqui) e as carpas comuns, Cyprinus spp. Quanto à idade e tamanho, em ótimas condições ambientais (alimentação farta, pequena densidade de estocagem [50 animais $/ \mathrm{m}^{2}$ ] boa qualidade de água etc.), fêmeas de Dendrocephalus brasiliensis, aos 10 dias de vida, atingiram tamanho de $25 \mathrm{~mm}$, apresentando ovissaco bem desenvolvido e liberando cistos aptos à produção de náuplios. No que se refere à fecundidade, foi observado que o número de cistos está na dependência direta do tamanho da fêmea que, por sua vez, relaciona-se com as condições ambientais de cultivo. Portanto, uma fêmea de 1,0 $\mathrm{cm}$, produz menos cistos que uma fêmea de $1,5 \mathrm{~cm} \mathrm{e}$ assim por diante (Figura 04).



Figura 04 - Número médio de cistos produzidos por fêmea em relação ao comprimento total $(\mathrm{cm})$. 
A relação macho/fêmea obtida no período amostral foi de 1 macho para cada 1,07 fêmea. A proporção sexual dos 23.890 espécimes analisados no período de um ano mostrou que 12.362 eram fêmeas e 11.528 eram machos, representando $51,75 \%$ e $48,25 \%$, respectivamente. O número de indivíduos por sexo, o comprimento médio e respectivo desvio padrão para machos e fêmeas, por mês de amostragem e período do ano (chuvoso e seco) são apresentados na Tabela 1. A hipótese de que o número de machos e fêmeas na população é diferente $\left(\mathrm{H}_{\mathrm{o}}\right.$ rejeita $\left.\mathrm{H}_{\mathrm{a}}\right)$ foi confirmada, após ter sido aplicado o teste $\chi^{2}(a=0,05)$. Para análise da proporção sexual por período (chuvoso e seco), do total de 23.890 indivíduos amostrados, 11.931 ocorreram no período chuvoso com uma proporção sexual de $57,22 \%$ de fêmeas contra $42,78 \%$ de machos. No período seco foram amostrados 11.959 , sendo $46,28 \%$ de fêmeas e $53,72 \%$ de machos.

Tabela 1 - Número de indivíduos de D. brasiliensis, amostrados por sexo nos períodos chuvoso e seco

\begin{tabular}{cccccc}
\hline \multicolumn{2}{c}{ Período } & \multicolumn{2}{c}{ Chuvoso } & Macho & Feco \\
\hline Ano & Mês & Macho & Fêmea & 1.005 & 280 \\
\hline 2004 & Dez. & & & 953 & 1.343 \\
2005 & Jan. & & 905 & 1.212 \\
& Fev. & & & & \\
& Mar. & 789 & 1.404 & & \\
& Abr. & 959 & 1.319 & & \\
Maio & 944 & 1.162 & & \\
& Jun. & 593 & 710 & & \\
& Jul. & 1.324 & 1.398 & 618 & 707 \\
& Ago. & 495 & 834 & 1.600 & 5.535 \\
& Set. & & & 1.299 & \\
\hline
\end{tabular}

Quanto ao período de desova, foi observado nesta espécie que sua reprodução ocorre ao longo de todo ano, pois todas as fêmeas coletadas estavam ovígeras. Os índices gonadossomáticos das fêmeas, para os períodos chuvoso e seco, apresentaram-se diferentes. No período seco como um todo ocorreu o maior índice gonadossomático (média de $0,40 \pm 0,19$ ), com destaque para os meses de dezembro e janeiro ( 0,43 e 0,65 respectivamente). No período chuvoso, os maiores IGS ocorreram nos meses de maio a julho $(0,36 ; 0,71$ e 0,35 , respectivamente). A média no período foi de $0,32 \pm 0,21$.

A periodicidade de reprodução ocorre inicialmente em indivíduos com idade média de 10 dias, quando bem desenvolvidos. A princípio não ocorre recrutamento. Após a liberação de cistos, não há realização de outra postura no mesmo período. Em viveiros de cultivo, essa periodicidade pode ser controlada de $30 \mathrm{em} 30$ dias com o esvaziamento dos viveiros, adubação e enchimento. Os cistos ficam então no ambiente de cultivo que, quando seco e inundado novamente, dá prosseguimento à nova população.

O tempo de vida máximo observado em $D$. brasiliensis nos viveiros e nos aquários foi de 70 dias. O resultado dos náuplios criados em aquários até a fase adulta para melhor se observar o comportamento reprodutivo, visando a confirmar o tipo de reprodução, mostrou que ocorre cópula caracterizando reprodução sexuada. O comportamento de cópula ocorre através de corte do macho que, em questão de segundos, segura a fêmea e a fecunda liberando-a em seguida.

Os náuplios criados isolados individualmente a partir do período larval e até a fase adulta apresentaram os seguintes resultados: as fêmeas mesmo aos 20 dias de nascidas não apresentaram cistos no ovissaco; observou-se ovissaco vazio e presença de oócitos no ovário, que não se desenvolveram, permanecendo neste estágio de desenvolvimento. No entanto, as fêmeas criadas junto com machos mesmo nos pequenos aquários apresentaram cistos no ovissaco com capacidade reprodutiva.

Os exemplares estudados encontram-se no mini-museu da Estação de Piscicultura de Paulo Afonso (EPPA), pertencente à CHESF - Paulo Afonso, Bahia. 


\section{DISCUSSÃO}

O crescimento em peso é determinado ontogeneticamente, podendo variar entre os sexos, fases de maturação ou mesmo entre populações de localidades distintas (HARTNOLL, 1982).

A análise da relação $\mathrm{Wt} / \mathrm{Lt}$ revelou que as constantes de crescimento em peso (b) determinadas para $D$. brasiliensis estão dentro do limite estabelecido para outros organismos aquáticos (LE CREN, 1951).

Segundo RABET \& THIÉRY (1996), Dendrocephalus ocorrem em viveiros de cultivo de forma densa, convivendo com peixes jovens, particularmente a Tilápia.

A reprodução de D. brasiliensis está intimamente relacionada com a qualidade da água e com a abundância de alimentos. Também a temperatura e a luminosidade estão fortemente ligadas ao ciclo reprodutivo desse Anostraca. Esses fatores são determinantes nas flutuações sazonais que se observam nas populações como consequência das alterações de equilíbrio entre os aumentos populacionais. Assim, o conhecimento básico dos processos que ocorrem em viveiros de cultivo é de suma importância para o desenvolvimento e manejo produtivo de muitos organismos, inclusive $D$. brasiliensis, que nasce e cresce rapidamente nos viveiros logo após seu enchimento (LOPES et al., 2008).

Na Estação de Piscicultura da CHESF em Paulo Afonso (BA), em dois viveiros de $2000 \mathrm{~m}^{2}$ cada, durante o período chuvoso, o total de biomassa obtido foi de $65 \mathrm{~kg}$ durante o ciclo de 15 dias e de $41,5 \mathrm{~kg}$ durante os 15 dias de cultivo no período seco. Pelos resultados obtidos, verificou-se que é possível produzir em torno de $2.000 \mathrm{~kg}$ de biomassa de branchoneta por hectare/ano nessas condições ambientais (LOPES et al., 2007).

Segundo PINHEIRO \& FRANSOZO (1993), a constante de crescimento em peso (b) é espécieespecífica, ocorrendo alterações em função do mês, estação do ano ou geograficamente, em função da heterogeneidade ambiental.

A taxa de crescimento em peso dos machos (b) foi superior à das fêmeas, resultado similar ao obtido por PINHEIRO \& FABIANO (2005), em Dilocarcinus pagei.

As fêmeas apresentaram melhor crescimento em peso no período chuvoso $(b=0,3290)$, certamente em função de seu período reprodutivo, quando as gônadas encontram-se maiores e mais pesadas. $\mathrm{O}$ IGS nesse período apresentou-se mais elevado nos meses de maio a julho. No mês de junho, o IGS foi o mais elevado do ano. No entanto, foi no período seco como um todo que o IGS apresentou-se mais elevado e com os meses de dezembro e janeiro (seco) semelhantes ao mês de junho (chuvoso). Esses resultados demonstraram que a espécie apresenta um período reprodutivo prolongado estendendo-se ao longo do ano.

Segundo HILL \& SHEPARD (1997), o diâmetro dos cistos não é um parâmetro válido para identificar todas as espécies de Dendrocephalideos. A espécie que pode ser identificada somente pelo diâmetro dos cistos é a Branchinecta gigas, que tem cistos de grande diâmetro.

Com referência aos cistos de branchoneta, esses também apresentam uma grande vantagem em relação aos de Artemia. O diâmetro dos cistos de Dendrocephalus brasiliensis foi de $219 \mu \mathrm{m}$ (OLIVERA, 2000), assemelhando-se com o diâmetro encontrado por RABET \& THIÉRY (1996) para $D$. brasiliensis, que foi de 213 a $233 \mu \mathrm{m}$ com uma média de $219 \pm 6.76 \mu \mathrm{m}$, e para Dendrocephalus ornatus, que foi de 208 a $260 \mu \mathrm{m}$ com uma média de $239 \pm 9.47 \mu \mathrm{m}$, enquanto o de Artemia gira em torno de $270 \mu \mathrm{m}$. Esse menor tamanho dos cistos de Dendrocephalus também propicia melhor aproveitamento direto como alimento para larvas de camarões ou peixes, após descapsulados.

Quanto ao porte alcançado pela branchoneta, verifica-se que esses crustáceos podem alcançar, em 15 dias de cultivo e em condições propícias, comprimento entre 1,5 e $2,0 \mathrm{~cm}$, constituindo uma vantagem sobre o Anostraca Artemia, considerado o principal expoente desse grupo. Esse fator confere à branchoneta um maior rendimento de biomassa, que poderá ser utilizada para a alimentação de peixes carnívoros e/ou outras espécies de peixes como os ornamentais, como alimento vivo ou congelado.

BEUX \& ZANIBONI FILHO (2007), pesquisando a sobrevivência e crescimento de Pseudoplatystoma corruscans (Pintado) alimentados com naúplios de Artemia sp. em diferentes salinidades, verificaram que as pós-larvas dessa espécie tiveram uma reduzida sobrevivência e a causa provável foi o fato de os náuplios de Artemia sp. morrerem rapidamente na água doce e se depositarem no fundo dos tanques prejudicando a qualidade da água de cultivo. Nesse caso, por se tratar de animal de água doce, D. brasiliensis, apresenta maior potencial na alimentação de organismos cultivados em água continental.

O encistamento dos embriões, o tipo de desova ovípara e a postura em massa de cistos pelas fêmeas também caracterizam uma evolução dessa espécie, já que os cistos postos em um meio ambiente favorável ou não para seu desenvolvimento ficam protegidos e os náuplios eclodem quando as 
variáveis físico-químicas do ambiente favorecem seu desenvolvimento.

Tem-se na região Nordeste do Brasil várias áreas com condições climatológicas e hidrológicas que favorecem o desenvolvimento e a produção de cistos e biomassa de branchoneta (OLIVERA, 2000).

Com referência à coloração dos Dendrocephalus, foi verificada a mudança de cor quando da alta ou baixa densidade de estocagem. Quando a densidade de estocagem é alta, observamse animais pequenos $( \pm 0,5 \mathrm{~cm}$ em 15 dias $)$ e coloração quase transparente influenciando também na identificação dos sexos. Quando a densidade é baixa, os animais apresentam tamanhos dentro do limite para a idade $( \pm 2,0 \mathrm{~cm}$ em 15 dias $)$ e coloração verde-azulada para machos e verde-rosada para as fêmeas. Acredita-se que isso se deve à ausência de algas provocada pela herbivoria no primeiro caso e à abundância no segundo caso. Os calanóides frequentemente armazenam alimento em câmaras especiais no intestino médio. Em consequência, sua cor transparente é substituída por uma coloração vermelha (devido à presença de carotenóides), azul ou verde (devido à carotenoproteínas) (ESTEVES, 1998).

MAEDA-MARTINEZ et al. (1995) descreveram que a coloração em filopodas é altamente variável, diferindo de lugar para lugar e de um estágio de vida para outro. PENNAK (1989) aponta que as cores vão desde o translúcido ou esbranquiçado até o cinza, azul, verde, laranja e avermelhado, provavelmente causados por uma grande variedade de alimentos ingeridos.

Quanto ao sexo nos Dendrocephalus, esse é facilmente identificado aos seis dias de vida, fato que também é confirmado no Anostraca Thamnocephalus platyurus que, entre 6 e 11 dias, já tem suas características sexuais definidas.

LOPES et al. (2006), comparando o crescimento (peso e comprimento) e a sobrevivência, durante 60 dias de cultivo, de um grupo de alevinos da espécie Pterophyllum scalare (Acará bandeira), alimentados com $D$. brasiliensis, e outro grupo de alevinos da mesma espécie, alimentados com ração floculada para peixes ornamentais, encontraram os seguintes resultados: peso médio de $9,95 \pm 2,59 \mathrm{~g}$, comprimento médio de 9,64 $\pm 23,03 \mathrm{~mm}$ e sobrevivência de $88 \%$ para alevinos alimentados com $D$. brasiliensis, e peso médio de $3,30 \pm 0,77 \mathrm{~g}$, comprimento médio de $58,20 \pm 6,82 \mathrm{~mm}$ e sobrevivência de $53 \%$ para os alevinos alimentados com ração floculada.

LOPES \& TENÓRIO (2005) observaram que, ao acompanhar a dieta alimentar de alevinos de Lophiosilurus alexandri (Niquim), em tanques, ocorre o consumo imediato de $D$. brasiliensis, mesmo mortos. Tais resultados enaltecem a importância desse crustáceo como alimento vivo destinado à alimentação de peixes, sendo de suma importância o domínio de sua reprodução.

Existem semelhanças entre os ciclos de vida e o processo de reprodução desse anostráceo com Artemia sp. no que se refere à presença constante de machos de geração a geração. Em Artemia ocorre tanto a reprodução sexuada com liberação direta de náuplios como a assexuada por meio de ovos de resistência. Em Dendrocephalus, não se tem observado reprodução sexuada com liberação de náuplios como ocorre com Artemia, levando a crer na reprodução sexuada somente com liberação de cistos.

Em determinadas épocas do ano, dependendo das condições ambientais, há um maior direcionamento para machos, chegando algumas vezes a $70 \%$ destes em relação às fêmeas. Os machos, maiores que as fêmeas, apresentam antênulas maiores e presença de ganchos no aparelho bucal indicando sua utilização para cópula.

A reprodução por partenogênese ocorre em rotíferos e cladóceros, mas, em determinadas épocas do ano em circunstâncias de pressão ambiental (quase sempre densidade populacional muito elevada), aparecem os machos e ocorre a reprodução sexuada. Na reprodução por partenogênese nos rotíferos, as fêmeas são amícticas, diplóides e produzem ovos amícticos que se desenvolvem para dar fêmeas amícticas que não necessitam de machos para fecundação. Em $D$. brasiliensis não se identificou esse fato, e acredita-se ser a presença de machos associada à pressão ambiental (elevada densidade populacional que interfere na alimentação disponível à sobrevivência) uma forma de controle populacional.

Segundo SALAZAR et al. (2003), os anostráceos de água doce possuem alta fecundidade e podem ser cultivados com êxito em condições controladas utilizando-se como dieta microalgas, levedura, aglomerados de bactérias e cianofíceas, sendo esses alimentos mais convenientes e econômicos para o crescimento e a reprodução. Em trabalho desses autores com a espécie $D$. geayi, foi possível se obter, em média, 1247 cistos por fêmea. Tal resultado se assemelha aos obtidos com $D$. brasiliensis quando em tamanho de $2,5 \mathrm{~cm}$. O encistamento de embriões, tipo de desova ovípara e a postura em massa também caracterizam uma evolução dessa espécie, já que os cistos liberados no meio ambiente, quando adverso para seu desenvolvimento, ficam protegidos pelo córion e eclodem quando as condições físicas e químicas se tornam favoráveis. 


\section{CONCLUSÃO}

Diante dos resultados encontrados a partir do comportamento reprodutivo da espécie em estudo, concluiu-se que Dendrocephalus brasiliensis apresenta reprodução sexuada com liberação de cistos independente das condições ambientais.

\section{REFERÊNCIAS}

BEUX, L.F.; ZANIBONI FILHO, E. Survival and the growth of pintado (Pseudoplatystoma corruscans) postlarvae on different salinities. Brazilian Archives of Biology and International Journal. V. 50, n.5, p. 821829. 2007.

CÂMARA, M.R. Artemia no Brasil: do extrativismo ao cultivo. Revista Panorama da Aqüicultura, v. 10, n.62, p 15-19, 2000.

COHEN, R.G. Crustacea Anostraca in: Lopretto e Tell (Eds.) Ecossistemas de Águas Continentais: Metodologia para su Estudio. La Plata, Editiones SUR - Tomo II. p. 871-895. 1995.

ESTEVES, F.A. Fundamentos de Limnologia. Editora Interciência Ltda, 1998 p. 127-128..

HARTNOLL, R. G. Growth, p. 111-185. In: D. E. Bliss (Ed.). The Biology of Crustacea. Embriology, Morphology and Genetics. New York, New York Academic Press, vol. 2, 1982.383 p.

HILL, R.E. e SHEPARD. W.D. Observations on the Identification of California Anostracan Cysts. Hydrobiology , v.359, p.113-123. 1997.

LE CREN, E. D. The lenght-weight relationship and seasonal cycle in gonad weight and condition in the perch (Perca fluviatilis). Journal of Animal Ecology, Oxford, v.20, n. 2, p. 201-219. 1951.

LOPES, J. P.; PONTES, C. S.; ARAÚJO, A. Fatores bióticos e abióticos que influenciam o desenvolvimento de branchoneta (Crustacea: Anostraca). Revista Brasileira de Engenharia de Pesca, v. 3, n. 1, p.76-90. 2008.

LOPES, J.P.; GURGEL, H.C.B.; ARAÚJO, A.; PONTES, C.S. Influência da inoculação de cistos na produção de biomassa de branchoneta (Dendrocephalus brasiliensis Pesta, 1921 (Crustacea: Anostraca). Revista Ciência e Agrotecnologia, v.32, n. 2, p. 598-603. 2008.

LOPES, J. P. Produção de cistos de branchoneta, Dendrocephalus brasiliensis (Crustacea: Anostraca). Revista Biotemas, v. 20, n. 2, p 33-39. 2007.

LOPES, J. P.; PONTES, C. S., ARAÚJO, A. A branchoneta na piscicultura ornamental. Revista Panorama da Aqüicultura, v. 94, p. 33-37. 2006.
LOPES, J.P.; TENÓRIO, R.A. A branchoneta (Dendrocephalus brasiliensis, Pesta 1921) como fonte de alimento para alevinos de niquim (Lophiosilurus alexandri Steindachner, 1876). Revista Nordestina de Zoologia, Maceió. v.2, n.1, p. 34-46, 2005.

MAI, M.G.; SILVA, T.A.S.; ALMEIDA, V.L.; SERAFINI, R.L. First Record of the invasion of Dendrocephalus brasiliensis Pesta, 1921 (Crustacea: Anostraca: Thamnocephalidade) in São Paulo State, Brazil. Pan-American Journal of Aquatic Sciences,v.3, n. 3, p. 269-274. 2008.

MAEDA-MARTINEZ, A. M, OBREGON, H. e DUMONT, H. J. Food-dependent color patterns in Thamnocephalus platyurus Packard (Branchiopoda: Anostraca); a laboratory study. Hydrobiology, v. 298, p. 133-139. 1995.

OLIVERA, A.G, SILVA, M.D.C.O e SANTOS, A.J.G. Reproductive potencial of Dendrocephalus brasiliensis and its use in Litopenaeus vannamei larval feeding. Universidade Federal Rural de Pernambuco. 2.000, 14p.

PENNAK, R.W. Enbranchiopoda (fairy, tadpole and clam shrimp), pp.326-349. IN: Freshwater invertebrates of the United States. Ronald Press, Nueva York. 1989.

PESTA, O. Kritische Revison der Branchipodidensammlung der Wiener Naturhistorischen. Annalen des Naturhistorischen Museums in Wien, v. 34 p. 80-98. 1921.

PINHEIRO, A.A. FABIANO, G.T. Relação peso/largura da carapaça e fator de condição em Dilocarcinus pagei Stimpson (Crustacea, Trichodactylidae), em São José do Rio Preto, São Paulo, Brasil. Revista Brasileira de Zoologia v. 22, n. 4, p. 825-829. 2005.

PINHEIRO, M.A.A \& FRANSOZO, A. Análise da relação biométrica entre o peso e a largura da carapaça para o siri Arenaeus cribrarius (Lamarck, 18818) (Crustácea, Portunidae). Arquivos de Biologia e Tecnologia Curitiba. v.36, n. 2, p. 331-341. 1993.

RABET, N; THIERY, A. The neotropical genus Dendrocephalus (Anostraca: Thamnocephalidae) in Brazil (South America), with a description of two new species. Journal of Natural History, v. 30, p. 479-503. 1996.

SALAZAR, B.H; DIAZ, J.V.G; SUAREZ, G.P.; SANCHEZ, D.J.T. Evaluación del efecto de dos dietas sobre la producción de biomassa y huevos de resitencia de Dendrocephalus geayi (Daday, 1908) (Crustacea: Anostraca: Thamnocephalidae). II Congresso Iberoamericano Virtual de Acuicultura. Venezuela. $\begin{array}{llll}\text { Resumen... } & \text { p. } & 534-539 . & \end{array}$ http://www.revistaaquatic.com/civa2003

VAZZOLER, A.E.A. de M. Biologia da reprodução de peixes teleósteos: teoria e prática. Maringá: NUPELIA, 169p. 1996. 